\title{
Exploring the velocity end of the force-velocity relationship in acyclic lower limb extensions
}

\author{
Jean Romain Rivière'1, Jean-Benoît Morin², Maximilien Bowen1', Laurent A. Messonnier ${ }^{1}$ and Pierre Samozino1 \\ 1 Univ Savoie Mont Blanc, Laboratoire Interuniversitaire de Biologie de la Motricité, EA 7424, F-73000 Chambéry, France \\ 2 Univ Lyon, UJM-Saint-Etienne, Laboratoire Interuniversitaire de Biologie de la Motricité, EA 7424, F-42023, Saint-Etienne, \\ France
}

Corresponding author: Dr. Jean Romain Rivière

Université Savoie Mont Blanc, STAPS, Campus scientifique, Le Bourget-du-Lac, 73376, France

Tel: + 33/479/75 8177 Fax: + 33/479/75 8148 Jean.r.riviere@gmail.com

\begin{abstract}
Purpose: compare linear and curvilinear models to describe the force-velocity relationship, especially on the velocity end, in lower limb acyclic extensions. Methods: nine athletes performed horizontal lower limb extensions on a leg press ergometer allowing to set from very high to very low (i.e. horizontal assisted extensions) resistive and inertial conditions. Lower limb force and velocity were continuously measured over the push-off in six resistive conditions to determine individual force-velocity relationships. Goodness of fit (GoF) of the linear model on force and velocity data (using the basic first order polynomial function), was compared to that of curvilinear models (using the basic second order polynomial function, Fenn and Marsh's, and Hill's equations) based on the Akaike Information Criterion (AIC). Results: When expressed relative to the theoretical maximal force $\left(F_{0-L}\right)$ and velocity $\left(v_{0}\right)$ obtained from the linear model, force and velocity data ranged from $26.6 \pm 6.6$ to $96.0 \pm 3.6 \% F_{0}$ - and from $8.3 \pm 1.9$ to $76.6 \pm 7.0 \% \mathrm{~V}_{0}$. $\mathrm{L}$ (range of individual values $=5-86 \% v_{0-\mathrm{L}}$ and $\left.16-99 \% F_{0-\mathrm{L}}\right)$. Curvilinear and linear models showed very high $\mathrm{GoF}(\mathrm{r} 2=0.951-0.999$; $\mathrm{SEE}=17-159 \mathrm{~N})$. Despite higher GoF for curvilinear models, AIC showed that the linear model presented $\sim 99-100 \%$ chance to be the best one to describe the force-velocity relationship. Conclusion: the force-velocity relationship in acyclic lower limb extensions can be considered as linear from its force (from $5 \% v_{0-L}$ ) to its velocity end (up to $86 \% v_{0-L}$ ). Assisted horizontal acyclic lower limb extensions allowed achievement of movement velocities very close to $v_{0}$, representing an interesting modality for training or testing force production capabilities at high velocities, notably for weaker populations.
\end{abstract}

Keywords: Horizontal leg press, Ballistic movements, Hill's equation, Fenn and Marsh's equation, Force production capabilities, Strength

Co-author agreement statement: We confirm that the manuscript has been read and approved by all named authors. We further confirm that the order of authors listed in the manuscript has been approved by all of us.

Preferred citation: Rivière J.R., Morin J.-B., Bowen M., Messonnier L.A., Samozino P. Exploring the velocity end of the forcevelocity relationship in acyclic lower limb extensions. SportRxiv, 2021

\section{Social Media handle:}

\section{Twitter}

Facebook 


\section{INTRODUCTION}

Many physical activities include lower limb ballistic extensions, which are often key to game winning actions or completion of daily tasks. Performance in such explosive efforts depends on the ability to produce high level of force and power over the entire movement within the shortest period of time. Maximal force and power generation capabilities during single ballistic multi-joint movements are well delineated by the linear force-velocity $(F-v)$ relationship and the resulting parabolic power-velocity $(P-v)$ relationship (1-3). These two relationships are associated to four variables: i) $F_{0}$, the force-intercept of the $F-v$ relationship, corresponding to the theoretical maximal force that could be produced at null velocity and representing the overall capabilities to produce force at low velocities; ii) $v_{0}$, the velocity-intercept of the $F$-v relationship, corresponding to the theoretical maximal velocity until which force could be produced and representing the overall capabilities to produce force at high velocities; iii) $P_{\max }$, the apex of the $P-v$ relationship corresponding to the maximal power value reached at optimal velocity $\left(v_{\text {opt }}\right)$; and iv) the individual mechanical $F$-v profile corresponding to the slope of the F-v relationship and representing its orientation towards force or velocity capabilities.

The assessment of $F-v$ and $P-v$ relationships in lower limb extensions can be done using cyclic movements, such as sprint running (4) or cycling (5). Although this method is advantageous to test individuals using sport-specific movements and in a safe, accessible, and reliable way $(6,7)$, it nonetheless includes movement-specific force orientation technique, which is less transferable from one physical activity to another. In contrast, during acyclic movements, such as vertical $(2,8)$ and horizontal $(9)$ jumping or lower limb extensions on an inclined or horizontal leg press devices $(1,10)$ the quasi-total external force developed by lower limbs is considered and so refer more to a non-specific strength index. However, due to the restricted range of velocity conditions in which force production is commonly measured, the linearity of the F-v relationship in acyclic movements has been questioned (e.g. Cuk et al. 2014; Ćosić et al. 2018). Indeed, these procedures include force production measurements only from $\sim 20$ to $\sim 50-60 \% v_{0}$, whatever the movement used $(8,9,11)$. As more than half of the $F-v$ relationship is typically undescribed by experimental data, it has been assumed that its apparent linearity would actually represent a partial range of an overall curvilinear relationship. The first argument to support this hypothesis is that the F-v relationship obtained from mono-articular movements or single-muscle in vitro conditions has been shown to be curvilinear. Indeed, during these specific experimental conditions the force was measured over a wide range of velocities and modelled with very high goodness of fit (GoF) by i) an exponential function, as suggested by Fenn and Marsh (F\&M'sEq; Fenn and Marsh 1935), ii) a reciprocal function (rectangular hyperbola), as proposed by Hill (Hill'seq; Hill 1938; Ritchie and Wilkie 1958; Hauraix et al. 2017), or iii) a combination of these two types of function, according to Edman's works (17). The second argument is that the basic second order polynomial (Poly2) and exponential functions show most of the time a higher GoF (i.e. higher coefficient of determination $\left[\mathrm{r}^{2}\right.$ ] and lower standard error of estimate [SEE]) than the basic first order polynomial function (Linear) on the typical range of $\sim 20$ to $~ 50-60 \% v_{0}$ in acyclic lower limb extensions (e.g. Cuk et al. 2014; Ćosić et al. 2018; Iglesias-Soler et al. 2019). However, in contrast to these two arguments, Bobbert (2012) showed that the relationship between external force and lower limb extension velocity is "quasi-linear" in a simulated leg press task, using a musculoskeletal model based on individual muscle force production capabilities defined by curvilinear F-v relationship using Hill'sEq.

To clarify the questioned linearity of the $F$-v relationship in acyclic lower limb extensions, several studies have experimentally explored its ends and compared the GoF of Linear to that of the curvilinear-shaped functions. On its force end (velocity conditions $<50 \% v_{0}$ ), the $F-v$ relationship was shown to be linear from $\sim 5 \% v_{0}(18,19)$, beyond which some studies argue that it would exist a breakpoint (20-23). From this breaking point, the force and velocity data would follow a curvilinear relationship, best modelled by Edman's exponential function (20-22). Nevertheless, in spite of this non-continuity of the linear curve, $F_{0}$ estimations from the curvilinear model were not 
significantly different and very close to the linear model (Alcazar et al. 2020). Consequently, the linear model could be used as the most relevant and the simplest one to accurately describe the entire $F$-v relationship on its force end and in turn determine $F_{0}(20)$. On the velocity end of the $F$-v relationship (velocity conditions $>50 \% v_{0}$ ), only the works of Yamauchi et al. have included measurements of lower limb force production up to $\sim 80-97 \% v_{0}$ (e.g. Yamauchi et al. 2007). They observed that Linear showed slightly higher GoF than the basic exponential function (Yamauchi et al. 2007). However, force and velocity measurements in these studies corresponded to peak values, which substantially influence the relative range covered by the experimental data, according to the joint angles at which the values are collected $(10,23)$. Thus, the shape of the $F$ - $v$ relationship on its velocity end remains unclear in acyclic lower limb extensions. In addition, Poly2 and Hill'sEq have never been compared to Linear considering experimental points markedly on the velocity end (i.e. $>50-60 \% v_{0}$ ) of the F-v relationship. Moreover, F\&M'SEq, firstly used to model the $F$-v relationship of single-muscle in vitro conditions (Fenn and Marsh 1935), has never been considered into the comparison of models on both ends of the relationship.

Models assessment performed in previous studies was based on testing significant differences between GoF of functions (i.e. $r^{2}$ and SEE). However, more complex functions, with greater number of degrees of freedom, will de facto fit better than a simpler one. Also, if significant differences exist between GoFs, such statistical approaches do not inform whether the additional degrees of freedom allow the model to describe more accurately the experimental data to an enough threshold that justifies the necessity to include them. In other words, they do not consider the principle of parsimony, which dictates that Numquam ponenda est pluralitas sine necessitate, as stated by William of Ockham (transl. plurality must never be posited without necessity; Ockham 1495). In the context of this study, "plurality" refers to models with higher degrees of freedom, which should not be preferred if simpler models are equally supported by experimental and statistical evidences (25). Otherwise, the higher the number of degrees of freedom, the higher the variance, which can lead to include random noise into the model, rather than relevant information, and in turn biased estimations of the outputs of interests (e.g. Fo or $v_{0}$; IglesiasSoler et al. 2019).

This study aimed to assess lower limb external force production on the velocity end of the force-velocity relationship in lower limb acyclic extensions and to compare i) the GoF of the linear model to curvilinear models and ii) their respective accuracy to describe experimental force and velocity data, considering the principle of parsimony. We hypothesized that, in spite of higher GoF of curvilinear models, their greater complexity would not improve the accuracy to describe the force and velocity data to an extent that would warrant their use instead of the simpler linear model.

\section{MATERIALS AND METHODS}

\section{Participants}

Nine healthy participants ( 8 males and 1 female, age $=21.3 \pm 0.5$ years, mass $=70.6 \pm 9.1 \mathrm{~kg}$ and height $=1.78 \pm 0.07 \mathrm{~m}$ ) gave their written informed consent to take part in this study, which was approved by the local ethics committee and complied with the standards of the declaration of Helsinki. All participants practiced regular physical activities (strength and endurance training) and were free of musculoskeletal pain or injury during the study.

\section{Design of the study}

The limitations of previous works to measure lower limb force production at extreme velocities during acyclic lower limb extensions could be due to the mechanical constraints imposed by the body weight and inertia in vertical movements or the remaining body inertia in horizontal movements. We addressed this issue by using an innovative leg press ergometer (vide infra). 
This study comprised three sessions separated by 24 to $48 \mathrm{~h}$ of rest. The first session familiarized participants to perform ballistic lower limb extensions on the ergometer at high force-low velocity and vice-versa. The two last sessions were dedicated to assess individual $F-v$ and $P-v$ relationships and both consisted of performing ballistic lower limb extensions in 6 different resistive conditions. Two sessions were planned to ensure that participants were able to maximize force production at very high velocities (e.g. Cuevas-Aburto et al. 2018).

\section{Ergometer}

The ergometer was a home-made instrumented horizontal leg press equipped with a flywheel surrounded by a friction belt. It is composed of a metal frame supporting a fixed seat and a rail, on which a chariot was free to slide along the direction of motion (i.e. direction of lower limb extension). The ergometer allows performing horizontal lower limb extensions without moving the body mass (i.e. only accelerating lower limb mass). More specifically, its design allows hip, knee and ankle extension in a body configuration close to starting position of jumping tests, without the movement of the upper-body. To allow reaching very high extension velocities, the ergometer also included an assistance mode with lateral traction springs (Figure 1). Participants sat with their feet on the chariot, their lower limbs flexed in a self-selected starting position. To stabilize participants' position on the seat, adjustable pads were lowered on their shoulders and a seat belt fastened over their trunk. Before each lower limb extension, the chariot was held with electromagnets controlled by the participant with a handheld button. For each lower limb extension, participants were asked to apply force on the chariot, which leads to its acceleration and the concomitant acceleration of the flywheel linked by a chain. Instantaneous linear and angular displacements of the chariot and the flywheel were measured with linear (Kübler Group, VillingenSchwenningen, Allemagne, $250 \mathrm{~Hz}$ ) and angular (Baumer, Fillinges, France, $250 \mathrm{~Hz}$ ) encoders, respectively. The friction forces applied by the belt on the flywheel $\left(F_{f b}\right)$ was measured with a strain gauge (Futek, Irvine, USA, $250 \mathrm{~Hz})$.

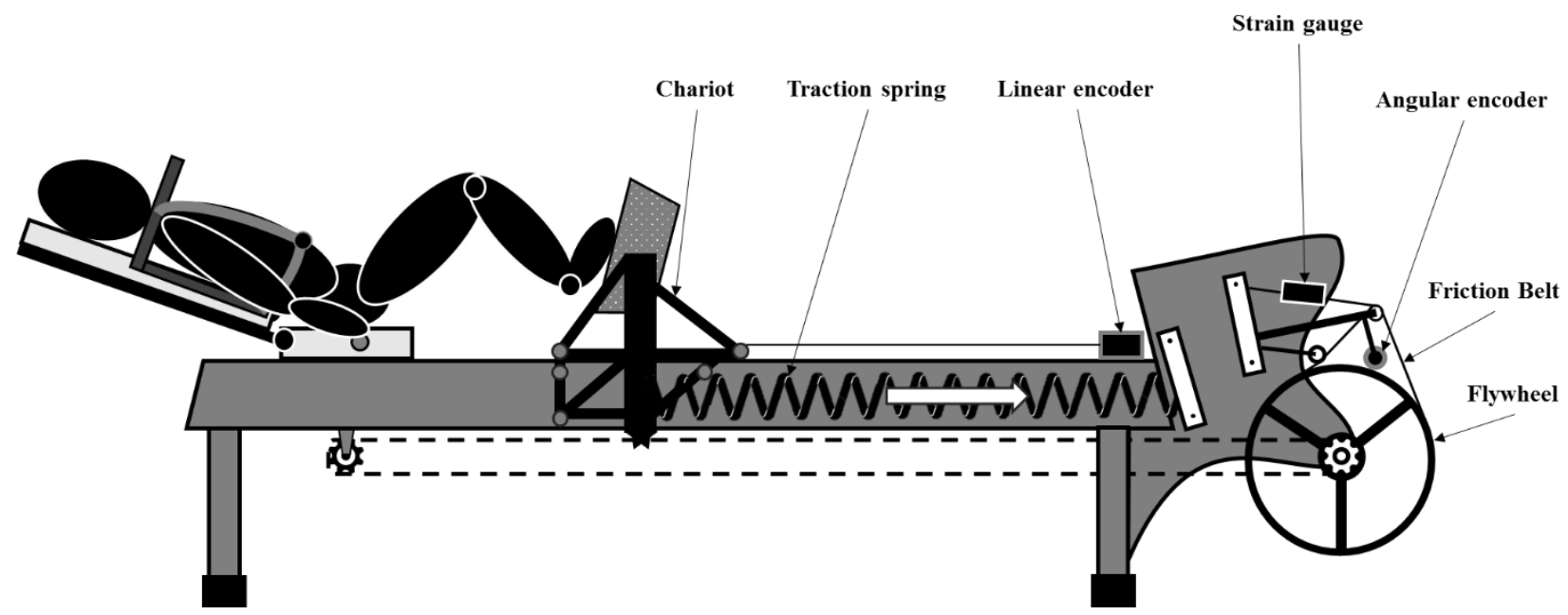

Figure 1. Schematic illustration of the instrumented horizontal leg press ergometer

\section{Protocol}

Each session started with a warm-up consisting of $\sim 15$ min of dynamic lower limb movements including sub-maximal and maximal unloaded squats, squat jumps and specific ballistic lower limb extensions on the ergometer at high force-low velocity and vice-versa.

The first session of familiarization started with the determination of individual's preferred starting position, in which the participant felt able to produce maximal force to initiate the lower limb extension. This individualized 
position was used for all subsequent trials. Then, participants performed twenty to thirty ballistic lower limb extensions on the ergometer in six different resistive and inertial conditions, as in the second and third sessions (detailed in the next paragraph). Two maximal voluntary isometric contractions were then performed on the ergometer with the friction force set at maximum, separated by at least 5 min of rest.

The second and third sessions aimed at determining individual $F-v$ and $P$ - $v$ relationships over the largest range of velocity conditions as possible. This required participants to perform ballistic lower limb extensions against six resistive conditions described here by decreasing amount of resistance: i) resistive frictional forces eliciting a movement velocity of $\sim 0.3 \mathrm{~m} . \mathrm{s}^{-1}$, which corresponds to the typical extension velocity observed when executing a one repetition maximum $\left(\mathrm{C}_{1 \mathrm{RM}}\right)$, ii) resistive frictional forces corresponding to $\sim 50 \%$ of maximal isometric force $\left(\mathrm{C}_{50 \%} \mathrm{Fmax}\right)$, only accelerating the chariot and the flywheel, the friction belt being removed, iii) with and iv) without two springs assisting the motion (CøFric-2S and CøFric-0s, respectively) and only accelerating the chariot, the chain between chariot and flywheel being removed, v) with and vi) without two springs in assistance ( $\mathrm{C}_{\text {char-2s }}$ and $\mathrm{C}_{\text {Char-0s, }}$ respectively; Table 1). Two to three trials were performed for each resistive condition. For each ballistic extension, participants were asked to trigger off the electromagnets and to hold lateral handles for upper-body stabilization, while producing as much force as possible and extending their lower limbs as fast as possible, aiming at throwing the chariot.

Table 1. Descriptive summary of the mechanical constraint and the force variables included in the computation, which was used to estimate the force developed over the lower limb push-off (Equation 1) in the six resistive conditions.

\begin{tabular}{|c|c|c|c|c|c|c|c|}
\hline \multirow[b]{2}{*}{ Condition } & \multirow[b]{2}{*}{ Description } & \multicolumn{6}{|c|}{$\begin{array}{l}\text { Force components included in the computation of the } \\
\text { lower limb force output }\end{array}$} \\
\hline & & $F_{\text {flywheel }}$ & $F_{\text {chariot }}$ & $\boldsymbol{F}_{\text {friction }}$ & $F_{\text {limbs }}$ & $F_{\text {roll }}$ & $F_{\text {spring }}$ \\
\hline $\mathrm{C}_{1 \mathrm{RM}}$ & $\begin{array}{l}\text { Acceleration of the chariot, the flywheel } \\
\text { with friction, and the lower limbs }\end{array}$ & + & + & + & + & + & - \\
\hline $\mathrm{C}_{50 \% \mathrm{Fmax}}$ & $\begin{array}{l}\text { Acceleration of the chariot, the flywheel } \\
\text { with friction, and the lower limbs }\end{array}$ & + & + & + & + & + & - \\
\hline Cørric-0S & $\begin{array}{l}\text { Acceleration of the chariot, the flywheel } \\
\text { (without friction), and the lower limbs }\end{array}$ & + & + & - & + & + & - \\
\hline Cørric-2S & $\begin{array}{l}\text { Spring assisted acceleration of the chariot, } \\
\text { the flywheel (without friction), and the } \\
\text { lower limbs }\end{array}$ & + & + & - & + & + & + \\
\hline $\mathrm{C}_{\text {Char-0S }}$ & $\begin{array}{l}\text { Acceleration of the chariot and the lower } \\
\text { limbs }\end{array}$ & - & + & - & + & + & - \\
\hline $\mathrm{C}_{\text {Char-2S }}$ & $\begin{array}{l}\text { Spring assisted acceleration of the chariot } \\
\text { and the lower limbs }\end{array}$ & - & + & - & + & + & + \\
\hline
\end{tabular}

The signs « + » et « - » correspond to the inclusion or the exclusion of the force component into the computation of the force developed by the lower limbs over the entire push-off, respectively.

\section{Data analysis}

During isometric tests, force output was measured with the strain gauge on the friction belt and the maximal isometric force was calculated as the mean force maintained during one second on the maximal force plateau. During lower limb extensions, as hip was fixed and feet were constantly in contact with the chariot, the

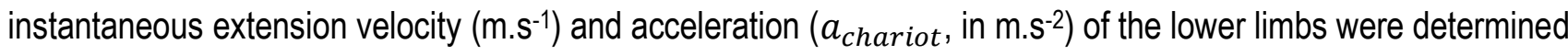
as first- and second-order derivative of the low-pass filtered $\left(20 \mathrm{~Hz}\right.$, Butterworth, $4^{\text {th }}$ order) position signal obtained from the linear encoder. During each trial of all conditions, the instantaneous force (in Newton) produced by lower 
limbs during the extension was computed using Equation 1 (detailed computations for each of the six resistive conditions in Table 1).

$F=F_{\text {flywheel }}+F_{\text {chariot }}+F_{\text {friction }}+F_{\text {limbs }}+F_{\text {roll }}-F_{\text {spring }}$

(Equation 1)

where $F_{\text {flywheel }}$ is the force to accelerate the flywheel (Equation 2), $F_{\text {chariot }}$ the force to accelerate the chariot (Equation 3), $F_{\text {friction }}$ the force to overcome the frictional forces applied by the belt on the flywheel (Equation 4 ), $F_{\text {limbs }}$ the force to accelerate the center of mass of the lower limbs (Equation 5), which was estimated from 2-D biomechanical model (detailed in the next paragraph), $F_{\text {roll }}$ the internal resistive force of the flywheel (6.06 $\mathrm{N})$ and $F_{\text {spring }}$ the force of the tension springs (Equation 6).

$$
\begin{aligned}
& F_{\text {flywheel }}=\frac{I \cdot \propto}{d_{p}} \\
& F_{\text {chariot }}=m_{\text {chariot }} \cdot a_{\text {chariot }} \\
& F_{\text {friction }}=F_{f b} \cdot \frac{d_{\text {flywheel }}}{d_{p}} \\
& F_{\text {limbs }}=m_{\text {limbs }} \cdot a_{\text {limbs }} \\
& F_{\text {spring }}=n \cdot(k \cdot x+b)
\end{aligned}
$$

where, $I$ is the moment of inertia of the flywheel $\left(0.131 \mathrm{~kg} \cdot \mathrm{m}^{2}\right), \propto\left(\mathrm{rad} . \mathrm{s}^{-2}\right)$ the instantaneous angular acceleration of the flywheel determined as second-order derivative of the low-pass filtered (20 Hz, Butterworth, 4th order) position signal obtained from the angular encoder, $d_{p}(\mathrm{~m})$ the cog radius, $m_{\text {chariot }}$ the mass of the chariot (15.15 $\mathrm{kg}$ ) including the mass of the chain $(1.05 \mathrm{~kg}), d_{\text {flywheel }}$ the radius of the flywheel, $m_{\text {limbs }}$ the masses of the lower limbs, $a_{\text {limbs }}\left({\left.\mathrm{m} . \mathrm{s}^{-2}\right)}^{2}\right.$ the instantaneous acceleration of the lower limb's center of mass estimated from the 2-D biomechanical model, $n$ the number of springs in assistance during the lower limb extension, $k$ the spring's

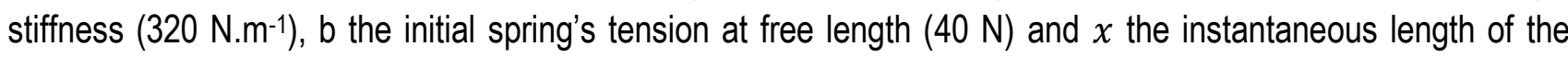
spring determined from the instantaneous position of the chariot. Note that the rolling friction of the chariot on the rail was negligible since counterbalanced by the very low linear encoder traction force $(\sim 0.01 \mathrm{~N})$.

As proposed by Rahmani et al. for bench press exercise, the use of simplified 2-D model with three segments is accurate enough to estimate center of mass displacement of the upper limbs (27). Thus, the 2-D model of the lower limbs used in the present study comprised three segments (thighs, shins and feet), which length and mass were estimated as a fraction of body height and mass, respectively, based on Winter's table (28). The model allows for the determination of the instantaneous horizontal center of mass' displacement of the three body parts during the lower limb extension, from which the instantaneous center of mass' displacement of the lower limbs was estimated.

Force, velocity and power were averaged over lower limb extensions, which started when $a_{\text {chariot }}$ became positive and ended when $a_{\text {chariot }}<-\frac{F_{\text {friction }}}{\left(m_{\text {chariot }}+m_{\text {limbs }}+m_{\text {flywheel }}\right)}$ (for conditions with the frictional forces on the flywheel) or when $a_{\text {chariot }}<0$ (for other conditions); with $m_{\text {flywheel }}(126 \mathrm{~kg})$ being the linear equivalent mass of the flywheel's moment of inertia, which was computed as : 
$m_{\text {flywheel }}=\frac{I}{d_{p}^{2}}$

(Equation 7)

For each participant, $F-v$ and $P-v$ relationships were determined from mean force, velocity and power values obtained from the best trial (i.e. highest mean power output) of the six different resistive conditions across all trials performed in the second and third sessions. Then, the mean force and velocity values of the best trials of six resistive conditions were fitted with Linear to model linear individual F-v relationships and with Poly2, F\&M'SEq and Hill'sEq to model curvilinear individual F-V relationships. As described by Hill in 1938, Hill'SEq corresponded to (15):

$F=\frac{\left(F_{0}+a\right) b}{v+b}-a$

(Equation 8)

where $F$ and $v$ correspond to mean force and velocity over lower limb push-off, and $a$ and $b$ are constants. Accordingly to the Fenn \& Marsh's work published in 1935, F\&M'SEq corresponded to (13):

$F=F_{0} e^{-A v}-B v$

(Equation 9)

where $A$ and $B$ are constants.

Based on the modelling of the F-v relationship with Linear, Poly2, F\&M'SEq and Hill'sEq, individual $F_{0}$ and $v_{0}$ values were computed as the force- and velocity-axis intercept, respectively. Individual $P$-v relationships were determined by integrating over velocity the $F-v$ relationship. Then, $P_{\max }$ and $v_{\text {opt }}$ were determined as the apex of the $P-v$ relationship and the velocity condition at which $P_{\max }$ occurred, respectively. The optimization procedure to fit the four functions on the experimental force and velocity data consisted of applying of least squares method with polynomial regression for Linear and Poly2 or the Levenberg-Marquardt algorithm for F\&M'SEq and Hill'SEq, with both optimization aiming to minimize the sum of squared errors. The Levenberg-Marquardt algorithm was set with $1.10^{7}$ evaluations of the model (i.e. number of evaluations of the loss function) and $1.10^{6}$ iterations (i.e. number of increments of the function's variables). As the Levenberg-Marquardt algorithm finds only a local minimum of the loss function, which is highly dependent on the starting values of the function parameters, the procedure of optimization was repeated one thousand times, considering at each repetition, a random starting value (within the range $[0 ;+\infty]$ and $[-100 ;+\infty]$ for Hill'sEq and F\&M'sEq, respectively).

\section{Statistical analysis}

All data are presented as mean \pm standard deviation (SD). To locate the mean force, velocity and power values obtained in the six resistive conditions, these outputs were expressed relative to $F_{0}, v_{0}$ and $P_{\max }$ obtained with the linear model $\left(F_{0-L}, V_{0-L}\right.$, and $P_{\text {max-L, }}$ respectively). When Hill'sEq was used, the magnitude of the curvature of the $F-v$ relationship was quantified by computing the ratio $a / F_{0}(15)$.

ANOVAs were performed to test the effect of the type of function (Linear, Poly2, F\&M'SEq and Hill'sEq) on $F_{0}$, relative-to-body-mass $F_{0}\left(R_{e} l F_{0}\right), v_{0}, P_{\max }$, relative-to-body-mass $P_{\max }(\operatorname{Rel} P \max )$ and $v_{\text {opt. }}$. These ANOVAs were performed after checking for distribution normality with Shapiro-Wilk's test and sphericity with Mauchly's test. If not met, a logarithm transformation was applied to restore normality without altering samples which initially met this statistical condition. If the assumption of sphericity was violated, the Greenhous-Geisser's correction was applied to reveal significant main effect of the type of model in ANOVAs. If the effect of the main factor was significant, Holm's post hoc test was used to highlight significant differences. The magnitude of the differences 
(i.e. the effect size; ES) between $F_{0}$, Rel $F_{0}, v_{0}, P_{\max }, \operatorname{Re} P_{\max }$ and $v_{\text {opt }}$ values from the four functions was assessed by standardization to the between-subject standard deviation. For all statistical analyses, a $p$-value of 0.05 was accepted as the level of significance. Hopkins' ES scale was used to describe these magnitudes with $<0.2,0.2$ to $<0.6,0.6$ to $<1.2,1.2$ to $<2.0$ and $>2.0$ representing trivial, small, moderate, large and very large effect, respectively (29).

$r^{2}$, SEE and residuals in force were computed to describe the GoF of the four functions. The magnitude of the differences between $r^{2}$ and SEE from the four functions was assessed using specific scales as proposed by Rudsits et al. (30). A clear improvement in $r^{2}$ was identified when its value increases from one magnitude threshold to the next threshold on the scale: $0.99,0.92,0.74,0.50$, and 0.20 . This scale was also used to describe the magnitude of $\mathrm{r}^{2}$ corresponding to extremely high, very high, high, moderate and low values, respectively to the scale. SEE values were compared using the same Hopkins' ES scale, but magnitude thresholds for assessing the standardized effect were halved (Rudsits et al. 2018).

As $r^{2}$, SEE and residuals in force do not represent criterions for model selection with parsimony and statistical inferences, curvilinear models were compared to the linear one using Akaike Information Criterion (AIC) analysis (for details, please see Akaike 1974). Briefly, this method was used to determine whether Poly2, F\&M'SEq and Hill'sEq lead to a sufficient improvement of the GoF to justify their higher complexity (i.e. higher number degrees of freedom), in comparison to Linear. To perform this test, i) the sum of standard error of each model (SSE), ii) the corrected AIC index (AICC; used instead of the AIC index due to the ratio sample size/degree of freedom being inferior to 40; Burnham and Anderson 2004), iii) the difference in AICc between the model with the smallest AICc and other models ( $\triangle \mathrm{AIC}$ ), iv) the relative likelihood of each model, v) the AICc weight (AICcw) for each model and vi) the relative and vii) absolute AICc evidence ratio ( $\left.A I C_{C_{W}-E R}\right)$ were computed. (for detailed definitions of these parameters, please see Johnson and Omland 2004).

\section{RESULTS}

Mean force, velocity and power developed over the push-off in the six resistive conditions are presented in Table 2 , in raw values and expressed relative to $F_{0-L}, V_{0-L}$ and $P_{\text {max-L, }}$ respectively.

Table 2. Mean \pm SD of mean absolute and relative force, velocity and power developed over lower limb extension in the six resistive conditions, as well as the range of individual values in brackets.

\begin{tabular}{|c|c|c|c|c|c|c|}
\hline & \multicolumn{2}{|c|}{ Force } & \multicolumn{2}{|c|}{ Velocity } & \multicolumn{2}{|c|}{ Power } \\
\hline & $\mathrm{N}$ & $\% F_{0-L}$ & $\mathrm{~m} \cdot \mathrm{s}^{-1}$ & $\% v_{0-L}$ & W & $\% P_{\text {max LL }}$ \\
\hline$C_{1 R M}$ & $\begin{array}{c}1703 \pm 325 \\
{[1373 ; 2337]}\end{array}$ & $\begin{array}{c}96.0 \pm 3.6 \\
{[94 ; 99]}\end{array}$ & $\begin{array}{l}0.29 \pm 0.08 \\
{[0.19 ; 0.46]}\end{array}$ & $\begin{array}{c}8.3 \pm 1.9 \\
{[5 ; 11]}\end{array}$ & $\begin{array}{l}492 \pm 130 \\
{[274 ; 662]}\end{array}$ & $\begin{array}{c}31.4 \pm 6.3 \\
{[19 ; 42]}\end{array}$ \\
\hline $\mathrm{C}_{50 \% \text { Fmax }}$ & $\begin{array}{l}1490 \pm 325 \\
{[1149 ; 2138]}\end{array}$ & $\begin{array}{c}82.0 \pm 3.7 \\
{[76 ; 88]}\end{array}$ & $\begin{array}{l}0.67 \pm 0.12 \\
{[0.50 ; 0.84]}\end{array}$ & $\begin{array}{c}19.0 \pm 2.2 \\
{[16 ; 23]}\end{array}$ & $\begin{array}{c}971 \pm 131 \\
{[800 ; 1173]}\end{array}$ & $\begin{array}{c}61.9 \pm 5.7 \\
{[55 ; 70]}\end{array}$ \\
\hline CøFric-0S & $\begin{array}{l}1147 \pm 155 \\
{[916 ; 1410]}\end{array}$ & $\begin{array}{c}64.1 \pm 6.7 \\
{[55 ; 75]}\end{array}$ & $\begin{array}{l}1.18 \pm 0.10 \\
{[1.03 ; 1.30]}\end{array}$ & $\begin{array}{c}34.3 \pm 5.6 \\
{[26 ; 41]}\end{array}$ & $\begin{array}{l}1366 \pm 261 \\
{[998 ; 1816]}\end{array}$ & $\begin{array}{c}87.0 \pm 8.8 \\
{[71 ; 94]}\end{array}$ \\
\hline CøFric-2S $_{\text {- }}$ & $\begin{array}{l}1001 \pm 134 \\
{[819 ; 1161]}\end{array}$ & $\begin{array}{c}56.2 \pm 7.7 \\
{[45 ; 66]}\end{array}$ & $\begin{array}{l}1.30 \pm 0.07 \\
{[1.13 ; 1.39]}\end{array}$ & $\begin{array}{c}37.5 \pm 4.7 \\
{[30 ; 45]}\end{array}$ & $\begin{array}{c}1299 \pm 174 \\
{[1095 ; 1547]}\end{array}$ & $\begin{array}{c}82.7 \pm 4.6 \\
{[78 ; 90]}\end{array}$ \\
\hline$C_{\text {Char-0S }}$ & $\begin{array}{c}628 \pm 53 \\
{[536 ; 711]}\end{array}$ & $\begin{array}{c}35.0 \pm 6.7 \\
{[24 ; 42]}\end{array}$ & $\begin{array}{l}2.27 \pm 0.21 \\
{[1.95 ; 2.63]}\end{array}$ & $\begin{array}{c}65.0 \pm 7.5 \\
{[56 ; 76]}\end{array}$ & $\begin{array}{c}1425 \pm 188 \\
{[1214 ; 1732]}\end{array}$ & $\begin{array}{c}89.0 \pm 9.9 \\
{[70 ; 100]}\end{array}$ \\
\hline $\mathrm{C}_{\text {Char-2S }}$ & $\begin{array}{c}465 \pm 88 \\
{[369 ; 612]}\end{array}$ & $\begin{array}{c}26.6 \pm 6.6 \\
{[16 ; 40]}\end{array}$ & $\begin{array}{l}2.67 \pm 0.25 \\
{[2.38 ; 3.08]}\end{array}$ & $\begin{array}{c}76.6 \pm 7.0 \\
{[64 ; 86]}\end{array}$ & $\begin{array}{c}1240 \pm 262 \\
{[1055 ; 1842]}\end{array}$ & $\begin{array}{c}79.5 \pm 13.4 \\
{[57 ; 100]}\end{array}$ \\
\hline
\end{tabular}


Typical examples of $F-v$ relationships drawn with the four functions, associated with their resulting $P$-v relationship, are presented in Figure 2. When using $H$ ill'sEq, al $F_{0}$ value was $1.06 \pm 0.72$. $F_{0}, R_{e} F_{0}, V_{0}, P_{\max }, \operatorname{Rel} P_{\max }$ and $v_{\text {opt }}$ values computed from each model are presented in Table 3 . When using Poly2, individual values of $v_{0}$ could not be calculated for eight participants, due to the absence of intercept with the velocity axis (see examples of two individuals on Figure 2, dashed black line on the left middle and bottom panels). ANOVAs indicated a significant main effect of the type of function on $F_{0}, R_{e} F_{0}, v_{0}, P_{\max }$ and $\operatorname{Re}_{\max } P_{\max }\left(\right.$ all $p<0.05 ; \omega^{2}=0.047,0.105$, $0.271,0.043$ and 0.102 , respectively), but not on $v_{\text {opt }}(p=0.380)$. Post-hoc analyses' $p$-values and effect sizes are presented in the Table 3. 


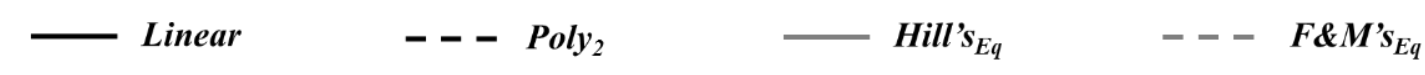

\section{Individual \#1}
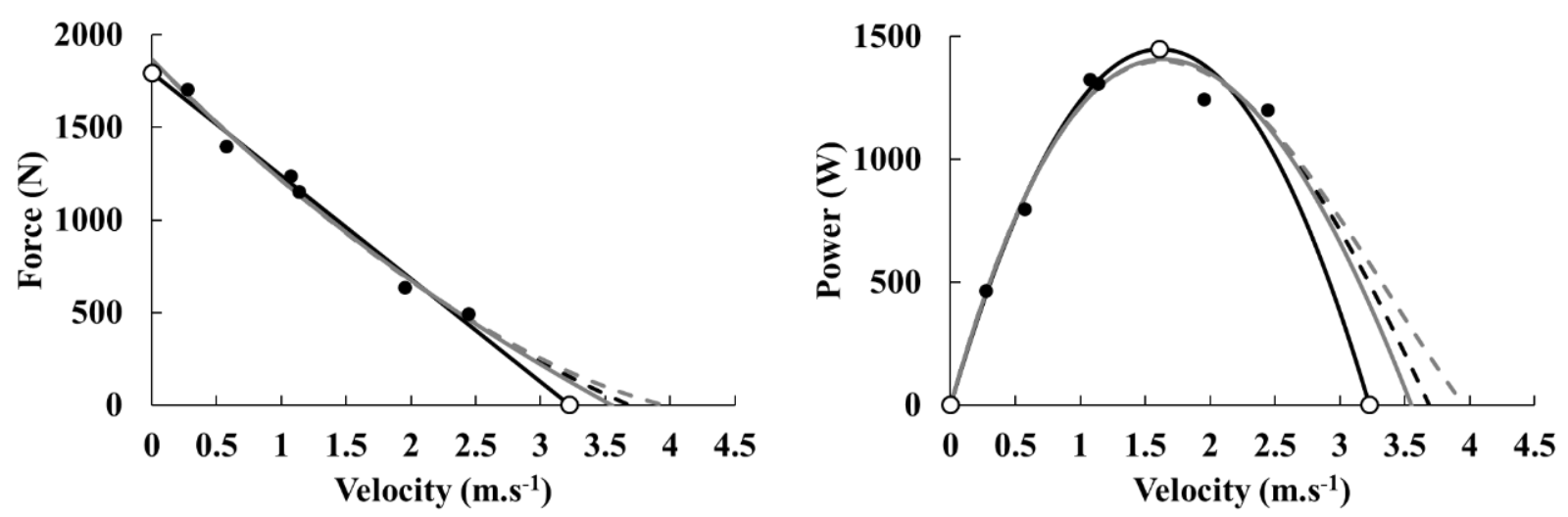

Individual \#4
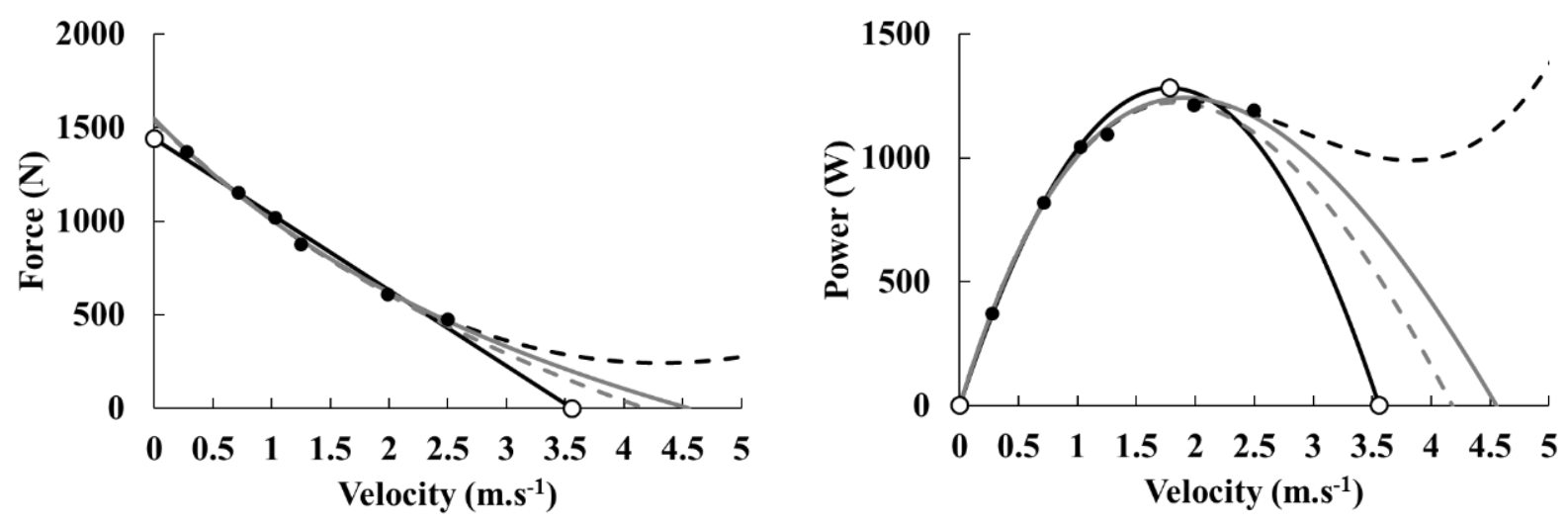

Individual \#7
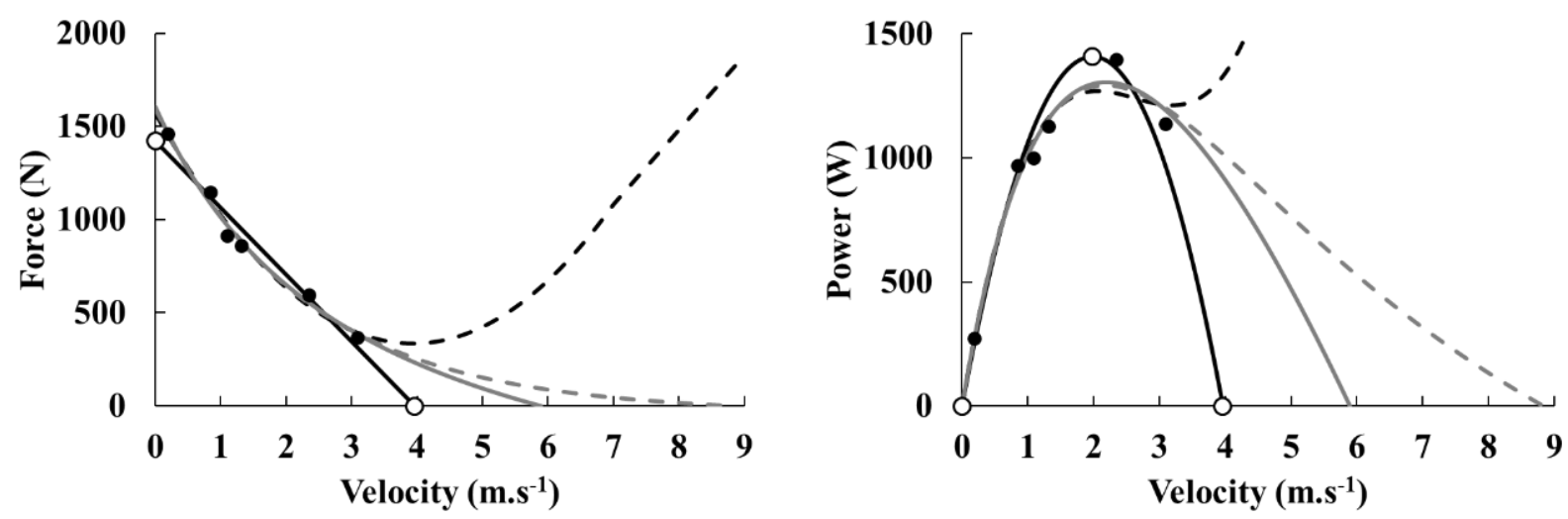

Figure 2. Three typical individual F-v relationships (left panels) drawn with Linear (solid black lines), Poly2 (dashed black lines), F\&M'sEq (dashed grey lines) and Hill'sEq (solid grey lines), associated with their resulting $P$-v relationships (right panels). Black points represent force, velocity and power data obtained from the six resistive conditions on the ergometer. The three individuals were chosen to represent typical examples of low (top panel; $a / F_{0}=2.70$ ), moderate (middle panel; $a / F_{0}=1.57$ ) and high (bottom panel; $a / F_{0}=0.53$ ) curvature of the F-v relationship when modelled with Hill'SEq. 
Table 3. Mean $\pm \mathrm{SD}$ and the range of individual values of $F_{0}$, Rel $F_{0}, v_{0}, P_{\max }$, Rel $P_{\max }$ and $v_{\text {opt }}$ determined from the four functions, as well as effect sizes of the difference between the linear and the three curvilinear models, associated to their interpretation and $95 \%$ confidence intervals in brackets.

\begin{tabular}{|c|c|c|c|c|c|c|c|}
\hline & & $F_{0}(\mathrm{~N})$ & $\operatorname{Rel} F_{0}(N / k g)$ & $v_{0}\left(m \cdot s^{-1}\right)$ & $P_{\max }(\mathrm{W})$ & $\operatorname{Rel} P P_{\max }(\mathrm{W} / \mathrm{kg})$ & $V_{\text {opt }}\left(m \cdot s^{-1}\right)$ \\
\hline Linear & $\begin{array}{l}\text { Raw values } \\
\text { [Individual values] }\end{array}$ & $\begin{array}{c}1810 \pm 339 \\
{[1421-2438]}\end{array}$ & $\begin{array}{c}25.6 \pm 3.3 \\
{[21.0-31.3]}\end{array}$ & $\begin{array}{l}3.52 \pm 0.54 \\
{[2.84-4.70]}\end{array}$ & $\begin{array}{c}1570 \pm 227 \\
{\left[\begin{array}{l}1 \\
282-1\end{array} 923\right]}\end{array}$ & $\begin{array}{l}22.3 \pm 1.7 \\
{[20.1-24.7]}\end{array}$ & $\begin{array}{c}1.76 \pm \\
0.27 \\
{[1.42-2.35]}\end{array}$ \\
\hline \multirow[t]{5}{*}{ Poly 2} & $\begin{array}{l}\text { Raw values } \\
\text { [Individual values] }\end{array}$ & $\begin{array}{c}1999 \pm 418 \\
{[1539-2664]}\end{array}$ & $\begin{array}{l}28.2 \pm 3.7 \\
{[22.3-34.2]}\end{array}$ & $\begin{array}{c}3.69 \pm 0.00 \\
x\end{array}$ & $\begin{array}{c}1456 \pm 212 \\
{[1231-1801]}\end{array}$ & $\begin{array}{l}20.7 \pm 2.0 \\
{[17.6-24.0]}\end{array}$ & $\begin{array}{c}1.99 \pm \\
0.82[1.30- \\
3.94]\end{array}$ \\
\hline & $\begin{array}{l}\text { Post-hoc's } p \text {-value } \\
\text { of the ANOVA }\end{array}$ & $p<0.001$ & $p<0.001$ & $x$ & $p<0.001$ & $p<0.001$ & $p=0.817$ \\
\hline & ES & 0.56 & 0.79 & $x$ & 0.50 & 0.94 & 0.85 \\
\hline & (Interpretation) & (Small) & (Moderate) & $x$ & (Small) & (Moderate) & (Moderate) \\
\hline & {$[95 \% \mathrm{Cl}]$} & {$[0.77 ; 0.35]$} & {$[0.55 ; 1.03]$} & $x$ & {$[0.32 ; 0.68]$} & {$[0.64 ; 1.25]$} & {$[0.76 ; 2.46]$} \\
\hline \multirow[t]{3}{*}{ Hill's $_{\mathrm{Eq}}$} & $\begin{array}{l}\text { Raw values } \\
\text { [Individual values] }\end{array}$ & $\begin{array}{c}2052 \pm 461 \\
{[1547-2716]}\end{array}$ & $\begin{array}{l}28.9 \pm 4.0 \\
{[22.3-34.8]}\end{array}$ & $\begin{array}{l}4.57 \pm 0.84 \\
{[3.55-5.91]}\end{array}$ & $\begin{array}{c}1471 \pm 211 \\
{[1243-1812]}\end{array}$ & $\begin{array}{l}20.9 \pm 1.9 \\
{[18.4-24.2]}\end{array}$ & $\begin{array}{c}1.84 \pm \\
0.33[1.52- \\
2.53]\end{array}$ \\
\hline & $\begin{array}{l}\text { Post-hoc's } p \text {-value } \\
\text { of the ANOVA }\end{array}$ & $p<0.001$ & $p<0.001$ & $p=0.013$ & $p<0.001$ & $p<0.001$ & $p=1.000$ \\
\hline & $\begin{array}{l}\text { ES } \\
\text { (Interpretation) } \\
{[95 \% \mathrm{Cl}]}\end{array}$ & $\begin{array}{c}0.71 \\
\text { (Moderate) } \\
{[0.39 ; 1.03]}\end{array}$ & $\begin{array}{c}1.00 \\
\text { (Moderate) } \\
{[0.62 ; 1.38]}\end{array}$ & $\begin{array}{c}1.96 \\
\text { (Large) } \\
{[1.35 ; 2.58]}\end{array}$ & $\begin{array}{c}0.43 \\
(\text { Small) } \\
{[0.28 ; 0.59]}\end{array}$ & $\begin{array}{c}0.67 \\
\text { (Moderate) } \\
{[0.56 ; 1.09]}\end{array}$ & $\begin{array}{c}0.30 \\
(\text { Small) } \\
{[0.11 ; 0.49]}\end{array}$ \\
\hline \multirow[t]{4}{*}{$F \& M{ }^{\prime} S_{\mathrm{Eq}}$} & $\begin{array}{l}\text { Raw values } \\
\text { [Individual values] }\end{array}$ & $\begin{array}{c}2029 \pm 443 \\
{[1535-2703]}\end{array}$ & $\begin{array}{l}28.6 \pm 3.9 \\
{[22.3-34.6]}\end{array}$ & $\begin{array}{l}5.22 \pm 1.63 \\
{[3.89-8.83]}\end{array}$ & $\begin{array}{c}1459 \pm 216 \\
{[1224-1810]}\end{array}$ & $\begin{array}{l}20.7 \pm 2.0 \\
{[17.8-24.1]}\end{array}$ & $\begin{array}{c}1.81 \pm \\
0.35[1.39 \\
2.55]\end{array}$ \\
\hline & $\begin{array}{l}\text { Post-hoc's } p \text {-value } \\
\text { of the ANOVA }\end{array}$ & $p<0.001$ & $p<0.001$ & $p<0.001$ & $p<0.001$ & $p<0.001$ & $p=1.000$ \\
\hline & $\begin{array}{l}\text { ES } \\
\text { (Interpretation) }\end{array}$ & $\begin{array}{c}0.65 \\
\text { (Moderate) }\end{array}$ & $\begin{array}{c}0.91 \\
\text { (Moderate) }\end{array}$ & $\begin{array}{c}3.17 \\
\text { (Very large) }\end{array}$ & $\begin{array}{c}0.49 \\
\text { (Small) }\end{array}$ & $\begin{array}{c}0.82 \\
\text { (Moderate) }\end{array}$ & $\begin{array}{c}0.18 \\
\text { (Trivial) }\end{array}$ \\
\hline & {$[95 \% \mathrm{Cl}]$} & {$[0.38 ; 0.92]$} & {$[0.29 ; 1.23]$} & {$[1.50 ; 4.85]$} & {$[0.32 ; 0.65]$} & {$[0.65 ; 1.21]$} & {$[0.04 ; 0.40]$} \\
\hline
\end{tabular}

GoF of the four functions, assessed with $\mathrm{r}^{2}$, SEE and the distribution of force residuals on the velocity conditions spectrum, are presented as individual values on the panels of Figures $\mathbf{3}$ and $\mathbf{4}$. Effect size of change in SEE were large, when comparing the Linear to the three other functions, but a clear improvement of $r^{2}$ was observed for only three participants (Figure 3, left panel). Variables associated to AICc analysis to compare the four functions are presented in Table 4. 

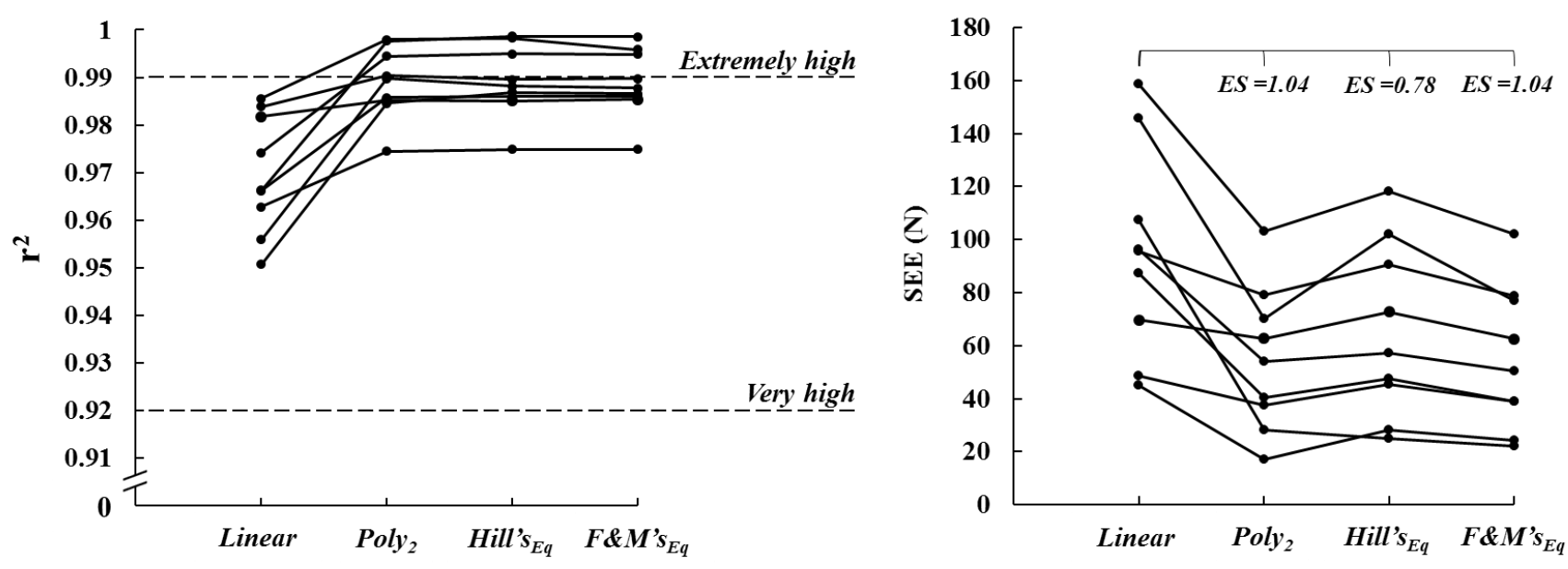

Figure 3. Differences in individual $\mathrm{r}^{2}$ and SEE for the four functions used. Effect size of these differences are represented as threshold with their interpretation on the left panel (black dashed line and text) and as raw values on the right panel (black horizontal brackets and text).

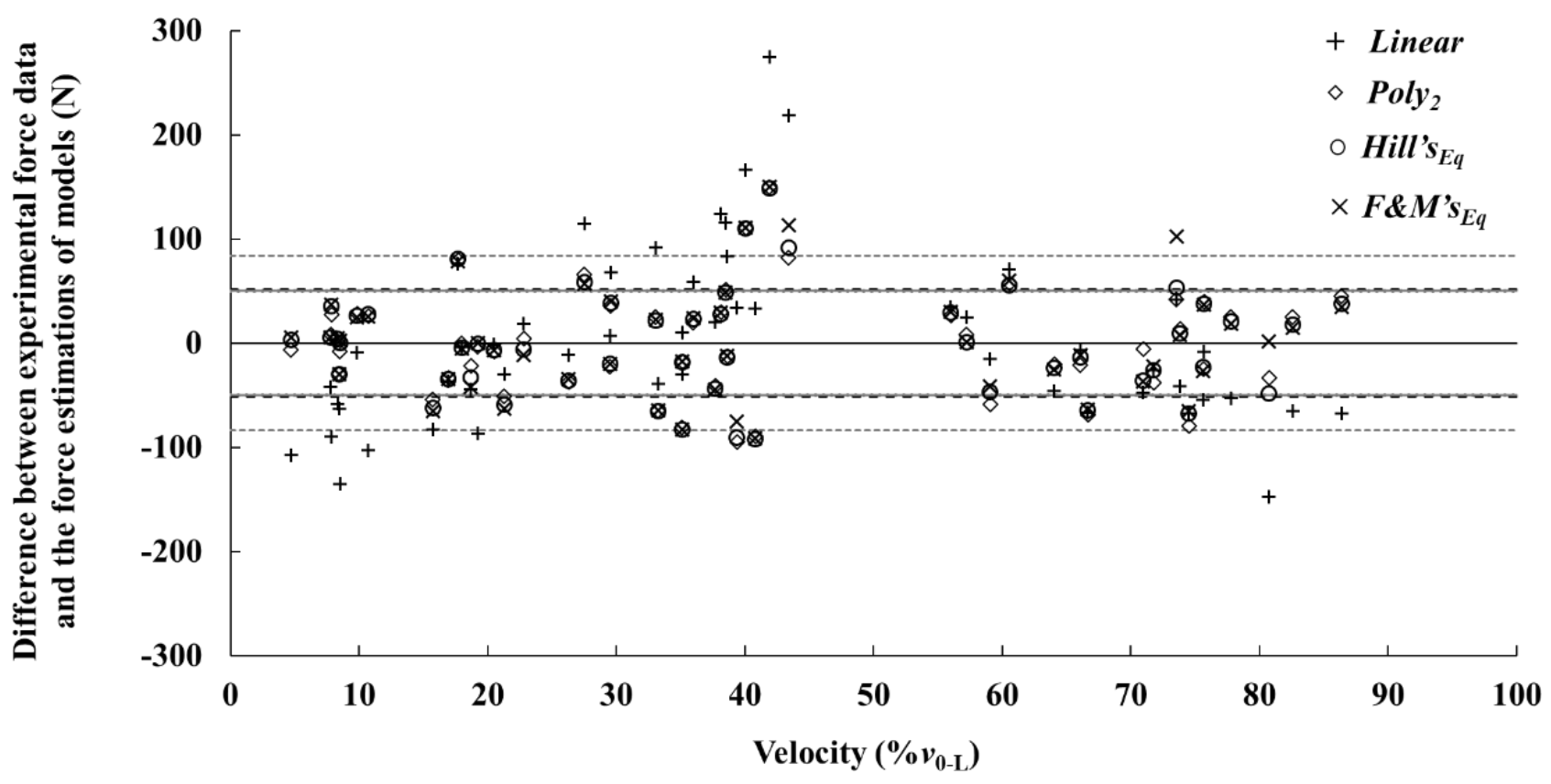

Figure 4. Distribution of residuals across participants presented according to the velocity condition. Residuals were computed as the difference between the force output during lower limb push-off in the 6 resistive conditions and the modeled force at the same velocity using Linear (black plus signs), Poly2 (Black diamonds), F\&M'SEq (black circles) and Hill'SEq (black crosses). SD of residuals for Linear, Polyz, Hill'SEq and F\&M'SEq are represented as dashed, dotted and full grey lines, and dashed black lines, respectively. 
Table 4. Mean $\pm \mathrm{SD}$ and individual values in brackets of $\mathrm{SSE}, \mathrm{AICC}, \triangle \mathrm{AICC}, \mathrm{AIC} \mathrm{C}_{\mathrm{w}}$, as well as absolute and relative $A I C C_{\mathrm{w}}-E R$, associated to their respective interpretations.

\begin{tabular}{|c|c|c|c|c|c|}
\hline & Interpretation & Linear & Poly 2 & $F \& M{ }^{\prime} s_{\mathrm{Eq}}$ & Hill's $_{\mathrm{Eq}}$ \\
\hline SSE (N²) & Sum of squared errors & $\begin{array}{l}40581 \pm 32443 \\
{[8111-100708]}\end{array}$ & 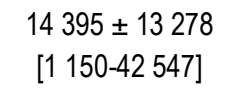 & $\begin{array}{c}15380 \pm 14256 \\
{[1846-41855]}\end{array}$ & $\begin{array}{c}14507 \pm 13311 \\
{[1980-41599]}\end{array}$ \\
\hline AlCc & $\begin{array}{l}\text { Index of information lost by the model to } \\
\text { approximate the observed data (estimation of } \\
\text { Kullback-Leibler information). The lower the } \\
\text { value, the lower the information lost, the closer } \\
\text { the model is to the "full reality". }\end{array}$ & $\begin{array}{l}69.054 \pm 5.244 \\
{[61.255-76.369]}\end{array}$ & $\begin{array}{c}91.884 \pm 6.825 \\
{[79.535-101.200]}\end{array}$ & $\begin{array}{c}92.188 \pm 6.754 \\
{[82.373-101.101]}\end{array}$ & $\begin{array}{c}92.031 \pm 6.487 \\
{[82.793-101.064]}\end{array}$ \\
\hline$\triangle \mathrm{AICC}$ & $\begin{array}{l}\text { AICc differences with respect to the AICc of the } \\
\text { best model. Allows for ranking models and } \\
\text { assessing their relative performance. }\end{array}$ & $\varnothing$ & $\begin{array}{c}22.830 \pm 4.822 \\
{[13.953-28.738]}\end{array}$ & $\begin{array}{c}23.134 \pm 5.457 \\
{[10.703-28.794]}\end{array}$ & $\begin{array}{c}22.977 \pm 5.302 \\
{[11.124-28.682]}\end{array}$ \\
\hline $\mathrm{AlC}_{\mathrm{w}}$ & $\begin{array}{l}\text { Relative weight of evidence for each model, } \\
\text { representing the probability that a model is the } \\
\text { best model for the observed data, given the } \\
\text { candidate set of models. }\end{array}$ & $\begin{array}{l}0.999 \pm 0.003 \\
{[0.991-1.000]}\end{array}$ & $\begin{array}{l}0.000 \pm 0.000 \\
{[0.000-0.001]}\end{array}$ & $\begin{array}{l}0.001 \pm 0.002 \\
{[0.000-0.005]}\end{array}$ & $\begin{array}{l}0.000 \pm 0.001 \\
{[0.000-0.004]}\end{array}$ \\
\hline$A I C c_{W-E R}$ & $\begin{array}{l}\text { Quantification of the strength of evidence in } \\
\text { favor of best model. In other words, answering } \\
\text { the practical question: how much less likely the } \\
\text { model is than the best model? }\end{array}$ & $\varnothing$ & 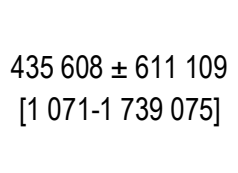 & $\begin{array}{c}472653 \pm 621639 \\
{[211-1788623]}\end{array}$ & $\begin{array}{c}446844 \pm 599662 \\
{[260-1690866]}\end{array}$ \\
\hline$A I C C_{W-E R}(\%)$ & $\begin{array}{l}\text { Ratio of } A I C C_{w} \text { of the compared model to the } \\
{\text { AIC } C_{w} \text { of the best model, corresponding to a }}_{\text {normalized probability that the best model is to }} \\
\text { be preferred. }\end{array}$ & $\varnothing$ & $\begin{array}{c}99.988 \pm 0.031 \\
{[99.907-100.000]}\end{array}$ & $\begin{array}{c}99.947 \pm 0.157 \\
{[99.528-100.000]}\end{array}$ & $\begin{array}{c}99.956 \pm 0.127 \\
{[99.617-100.000]}\end{array}$ \\
\hline
\end{tabular}

\section{DISCUSSION}

The main finding of this study was that the innovative leg press ergometer allowed lower limb external force production measurements over mean extension velocity conditions ranging from $\sim 0.3$ to $\sim 2.7 \mathrm{~m}^{-\mathrm{s}^{-1}}$

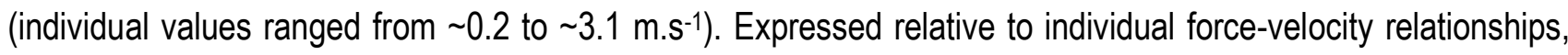
these ranges corresponded to $\sim 8$ and $\sim 77 \% v_{0}$-L, respectively (individual values ranged from $\sim 5$ to $\sim 86 \% v_{0}-\mathrm{L}$ ). The second main result was that, following the principle of parsimony, the linear model was much more likely the best model to describe the force-velocity relationship over the range 5-86 \% v0-L compared to curvilinear models.

The novel ergometer used in the present study allows ballistic and horizontal (i.e. without the resistance of the body weight) lower limb extensions, with assistance to the motion, without moving the upper-body mass and with low external masses involved (i.e. only lower limb and chariot masses). All the features of the ergometer resolved technical issues of previous studies, in which mean acyclic lower limb extension velocities in horizontal

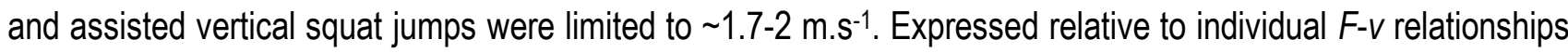
these ranges corresponded to $\sim 50-60 \% v_{0-L}$ and an exploration of 0-10\% on the velocity end $(9,11,34)$. In comparison, the low resistive and inertial conditions allowed by the ergometer was made it possible to explore 
the velocity end up to $\sim 27 \%$ (Table 2). It is worth noting that, in addition to very low resistive and inertial conditions, a technical assistance is required to guarantee the achievement of very high velocity conditions. Indeed, only five participants in this study reached velocity conditions higher than $60 \% v_{0-L}$ in the lowest resistive and inertial conditions without the spring assistance (i.e. C Char-os; Tables 1 and 2). Such technical assistance is necessary in acyclic lower limb extensions, because each single effort starts at null velocity, which requires the inertia of the moving masses to be overcome in each resistive/loading condition. In comparison, $v_{0-L}$ can be approached up to $\sim 90 \%$ in cyclic movements (e.g. running and cycling) without cumbersome methods and equipment, because high velocity lower limb extensions occur at the end of a $\sim 6$-s sprint, when the moving masses have been already accelerated $(5,35)$. Consequently, the measurement of lower limb force production during acyclic extensions in velocity conditions beyond 50-60\% $\%$ v-L cannot be performed, except by the means of an assistance, and very low resistive and inertial conditions.

The process of selecting the most accurate model to describe experimental data relies on i) their high GoF, ii) equality of distribution of residuals, as well as their magnitude across the experimental conditions, iii) avoiding unnecessary complexity (Occam's razor) and iv) verifying practical relevance and reliability of model outputs (32). In the present study, the four functions showed equally distributed residuals across velocity conditions (i.e. 5-86 \% vo-L range) and SDs of these residuals are within the low bandwidth of $100 \mathrm{~N}$ (Figure 4). These results highlight that all models describe with similar accuracy the force and velocity data over the entire experimental range tested. As a consequence, the function of each model fitted with very to extremely high quality on the force and velocity data, with low SEE (Figure 3). When comparing Linear to the three other functions, differences in SEE were large and a clear improvement of $r^{2}$ was observed for only three participants. These differences are mainly due to the few isolated cases of high errors for Linear (Figure 4). Overall, even if functions of curvilinear models showed slightly better GoF than Linear (e.g. Cuk et al. 2014; Iglesias-Soler et al. 2019; Alcazar et al. 2020), the GoF of all functions was within high to very high quality range. However, in spite of higher GoF for Poly2, Hill'sEq and F\&MEq, their greater degrees of freedom did not improve accuracy of $F$-v relationship description to an extent that warrants their utilization. Indeed, the linear model had $\sim 99 \%$ chance to be the best model and displayed extremely high strength of evidence in its favor (from 1071 to 1739075 and from 99.9 to $100.0 \%$ likelihoods; Table 4). This follows Occam's razor principle, which states that among all type of models giving similar accuracy, the one with the fewest assumptions and parameters should be used (24). Therefore, these results support the use of the linear model to adequately draw the $F-v$ relationship in acyclic lower limb extensions over the range $5-86 \%$ vo-L.

The validity of a model to describe the $F-v$ relationship relies on the practical and physiological relevance of its output parameters, which here correspond to $F_{0}, v_{0}$ and $P_{\max }$. The latter derived from the linear model have been widely investigated in acyclic lower limb extensions. So far, the reported $P_{\text {max-L }}$ values have been very close to the experimental power output measured at (or very close to) optimal velocity conditions in vertical squat jump (e.g. Cuk et al. 2014; Jaric 2015), which validates the physiological relevance of $P_{\text {max-L. In }}$ the present study, curvilinear models showed lower value of $P_{\max }$ than linear model (Table 3 ) in contrast to similar or higher values of $P_{\max }$ previously reported $(18,20)$. The higher $P_{\max }$ values obtained from curvilinear models were certainly due to a lack of experimental force and velocity collected below $50 \% F_{0}$ when fitting the linear model, which have led a lower $v_{0-\mathrm{L}}$ and, in turn, a lower $P_{\max -\mathrm{L}}(20)$. Aside from this methodology, the similar values of $P_{\max }$ were obtained between linear and curvilinear models due to the high number of resistive/loading conditions around the optimal velocity condition (18). The results of our study differ from those of Iglesias-Soler et al., as we chose to use six resistive conditions to assess the $F-v$ relationship. Regarding $F_{0}$, its estimation from the linear model here was small to moderately lower than curvilinear models, yet both type of models estimated $F_{0}$ values in line with usually reported lower limb dynamic maximal strength for recreational subjects (e.g. $\sim 1.5$ to 1.8 times body mass for half- 
squat 1-RM). However, both models can provide very close estimation (Iglesias-Soler et al. 2019) or quasi-similar values, when using high number of resistive/loading conditions very close to $F_{0}$ (Alcazar et al. 2020). Consequently, linear and curvilinear models cannot be challenged based on the physiological relevance of $F_{0}$ values. If $P_{\max }$ and $F_{0}$ values are quite within a similar range of physiological values for all models, $v_{0}$ values extrapolated from linear and curvilinear models are often different, and so their physiological relevance could be questioned. This could be investigated by measuring lower limb force production in the highest velocity conditions possible. This challenge was taken up in the present study and, although the velocity end of the F-v relationship

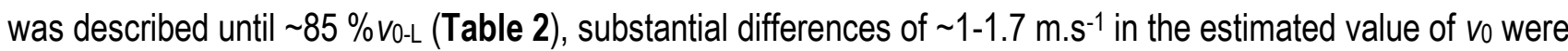
observed between linear and curvilinear models (Table 3). In comparison to vo values obtained from both type of models here, the biomechanical model proposed by Bobbert (2012), considering a curvilinear model (using Hill'SEq) to describe the F-v relationship of individual muscles involved into an acyclic lower limb extension,

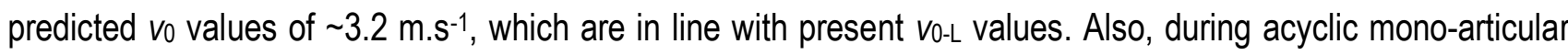
knee extensions under very low resistive and inertial conditions, the maximal angular velocity corresponded to $\sim 650$ and $750 \%$ s $(8,14)$. By using the 2-D model previously mentioned, these angular velocities would approximately correspond to lower limb extension linear velocity between of $\sim 2.5$ and $3 \mathrm{~m} . \mathrm{s}^{-1}$, respectively. Finally, the theoretical maximal pedaling cadences for active individuals (i.e. 230 rotations per minute; Dorel et al. 2010) and experimental maximal pedaling cadences of elite track cyclists $(\sim 270-300$ rotations per minute) would correspond (considering a typical crank length of $0.175 \mathrm{~m}$ ) to lower limb extension velocities of $\sim 2.7 \mathrm{~m} . \mathrm{s}^{-1}$ and $\sim 3.2-3.5 \mathrm{~m} . \mathrm{s}^{-1}$, respectively. Overall, these values from the literature are in line with the individual range of $v_{0}$ values estimated here from the linear model (Table 3 ) and largely lower than $v_{0}$ values extrapolated here from Hill'SEq and F\&MEq. Even if i) the compared values are representative of individuals with different training history and anthropometrical characteristics, and that ii) maximal lower limb extension velocity does not depend only on the maximal knee extension velocity, and that iii) pedaling and acyclic lower limb extensions are not exactly similar movements (e.g. differences in muscle activation dynamics), their closeness with $v_{0-L}$ values support the relevance of the latter and the potential overestimation of $v_{0}$ values estimated by curvilinear models in acyclic lower extensions. In addition, it is important to note that with the narrower typical range used, especially on the field, to assess the F-v relationship in acyclic lower limb extensions (i.e. $\sim 20$ to $\sim 50-60 \% v_{0}$ ), differences in estimated $v_{0}$ values between linear and curvilinear models would be greater. In fact, the narrower the range of velocity conditions, the more likely the occurrence of overestimated $v_{0}$ values. Consequently, the linear model should be preferred in this context, otherwise curvilinear models could give erroneous values of the maximal lower limb extension velocity. Besides, curvilinear models can lead to misleading values, lacking of physiological meaning, as discussed recently (18) or can lead to undefined values, as observed in the present study for eight participants out of nine (left middle and bottom panels, Figure 2). This tends to show that the function with a higher GoF does not systematically lead to a model with a greater physiological sense. It was the case here for Poly2, which showed the lowest SEE of all curvilinear models (Figure 3, right panel), but did not define any $v_{0}$ values for most participants. Consequently, the most appropriate model should not be selected according to the mathematical function which fits at best the experimental data, but rather on its ability to describe at best the properties of the system studied, which correspond here to human biological features of force production capabilities during a multi-joint movement. Overall, the available experimental evidence strongly supports the physiological relevance of $v_{0}$ obtained from the linear model, in comparison to the values estimated from the curvilinear models tested. It is important to note that, in the hypothetical case that the actual $F$ - $v$ relationship in acyclic lower limb extensions were not linear beyond $\sim 86 \% v_{0-L}$, it would not challenge the application of the linear model on the range 0-86\% $\%$ vo-L. Indeed, this range represents most of the practical field situations, with the linear extrapolation of $F_{0}$ and $v_{0}$ representing the theoretical limits of the neuromuscular system. Thus, the use of the 
linear model within this $\sim 86 \%$ range does not challenge scientific applications in performance, testing and training related to the linear model approach of the F-v relationship in multi-joint movements (e.g. Morin and Samozino 2018; Jiménez-Reyes et al. 2019).

The reliability of $F_{0}, v_{0}$ and $P_{\max }$ derived from the linear model has also been investigated in previous studies. High reliability has been often reported for $F_{0}$ and $P_{\max }$ and moderate to high reliability for $v_{0}$ in youth people, young and older adults $(11,36-38)$. So far, only one study has compared the reliability of outputs between linear and curvilinear models (using the basic exponential function and Poly2) on the range $\sim 10-50 \% v_{0-L}$ and showed similar (for $F_{0}$ ) and even lower reliabilities (for $v_{0}$ and $\left.P_{\max }\right)(18)$. However, it is important to note that such restricted range of velocity conditions will very likely reduce the reliability of the estimated parameters, especially from complex models, since the fitted curve of the latter is statistically more likely to change with error measurements. Consequently, even if the linear model seems to yield greater outputs reliability, further studies, considering a wider range of experimental velocity conditions, are required to clarify the comparison of outputs reliability of linear and curvilinear models in acyclic lower limb extensions, notably using F\&M'sEq and Hill'sEq.

Finally, the difference in the models used to describe $F$-v relationship in acyclic lower limb extensions and during single-joint or in vitro single-muscle contraction has been supported by the fact that the former refers to external rather than intrinsic muscle force production. Indeed, the former involves specific underlying mechanisms, including neural control of various muscle groups, activation and segmental dynamics, which are not all encompassed in the two later conditions $(2,3,10)$. In this sense, Bobbert (2012) reported a "quasi-linear" $F$-v relationship over a wide range of simulated velocity conditions ( $\left.\sim 5-90 \% \mathrm{~V}_{0-L}\right)$ in acyclic lower limb extensions, despite using Hill's curvilinear model to characterize intrinsic force production capabilities of individual muscles. Furthermore, the linearity of the F-v relationship in acyclic lower limb extensions is in line with the linearity observed in other multi-joint movements, such as cycling and running, where lower limb force production was measured over a wide range of velocity conditions, notably on the velocity end (i.e. 20-90 \% vo-L; Dorel et al. 2010; Morin et al. 2019).

\section{PERSPECTIVE}

The features of the ergometer used in this study allow force production measurements of the lower limbs from very low $\left(\sim 0.2 \mathrm{~m} . \mathrm{s}^{-1}\right)$ to very high $\left(\sim 3.1 \mathrm{~m} . \mathrm{s}^{-1}\right)$ velocity conditions. This highest velocity condition was $\sim 1 \mathrm{~m} . \mathrm{s}^{-}$ 1 greater than a horizontal squat $(9,34)$, which was the lowest constraining conditions to train velocity capabilities so far (i.e. $v_{0}$ ). This type of device could thus benefit health institutions to manage training of weak population with specific deficit in velocity capabilities (39). Thanks to the ergometer used, the F-v relationship can be evaluated i) without using additional loads, which may be safer notably for frail populations, and ii) on a wide range of velocity conditions, which could increase the accuracy and the reliability of $v_{0}$ and $P_{\max }$ determination (26). On the $\sim 5-86$ $\% v_{0-L}$ range, the linear model was the most appropriate to describe force and velocity data. As most field situations occur within this $\sim 81 \%$ range, using the linear model to describe the $F$-v relationship does not challenge testing and training methods related to the application of such model in multi-joint movements (e.g. Morin and Samozino 2018b; Jiménez-Reyes et al. 2019).

\section{CONCLUSION}

Assisted horizontal acyclic lower limb extensions without moving the rest of the body, performed thanks to an original horizontal leg press ergometer, allows achievement of movement velocities up to $86 \%$ v. Along with the lowest velocity condition $\left(\sim 5 \% v_{0}\right), \sim 81 \%$ of the entire $F-v$ relationship spectrum was covered. On this wide experimental range of force and velocity data, the $F-v$ relationship was adequately described by the linear model, the ratio between the higher complexity and goodness of fit of curvilinear models being considered as 
unfavorable. Further technical and methodological improvements of the ergometer could potentially help widen even more the range covered here and test the linearity of the $F-v$ relationship in velocity conditions superior than $90 \% v_{0}$.

\section{ACKNOWLEDGEMENTS}

We would like to show our gratitude to Baptiste Denopce and Nicolas Masson (master's students in engineering and ergonomics of physical activities at Université Savoie Mont Blanc) for their help during the experimental phase of this project. No funding was received for this work.

\section{CONCLIFT OF INTEREST}

The authors report no conflict of interest.

\section{REFERENCES}

1. Samozino P, Rejc E, Di Prampero PE, Belli A, Morin J-B. Optimal Force-Velocity Profile in Ballistic Movements-Altius. Med Sci Sport Exerc. 2012;44(2):313-22.

2. Jaric S. Force-velocity Relationship of Muscles Performing Multi-joint Maximum Performance Tasks. Int J Sports Med. 2015;36(09):699-704.

3. Bobbert MF. Why is the force-velocity relationship in leg press tasks quasi-linear rather than hyperbolic? J Appl Physiol. 2012;112(12):1975-83.

4. Morin JB, Samozino P, Bonnefoy R, Edouard P, Belli A. Direct measurement of power during one single sprint on treadmill. J Biomech. 2010;43(10):1970-5.

5. Dorel S, Couturier A, Lacour JR, Vandewalle H, Hautier C, Hug F. Force-velocity relationship in cycling revisited: Benefit of twodimensional pedal forces analysis. Med Sci Sports Exerc. 2010;42(6):1174-83.

6. Krüger RL, Peyrard A, di Domenico H, Rupp T, Millet GY, Samozino P. Optimal load for a torque-velocity relationship test during cycling [Internet]. Eur J Appl Physiol. 2020;(0123456789) available from: https://doi.org/10.1007/s00421-020-04454-x. doi:10.1007/s00421-020-04454-X.

7. Morin J-B, Samozino P. Biomechanics of Training and Testing. Cham: Springer International Publishing; 2018. Available from: http://link.springer.com/10.1007/978-3-319-05633-3.

8. Bosco C, Komi P V. Potentiation of the mechanical behavior of the human skeletal muscle through prestretching. Acta Physiol Scand. 1979;106(4):467-72.

9. Janicijevic D, García Ramos A, Knezevic O, Petrović MR, Mirkov D. Force-velocity relationship of lower-body muscles during horizontal during jumps-preliminary results. Niš, Serbia: XXI Scientific Conference "FIS COMMUNICATIONS 2018" in physical education, sport and recreation; 2018.

10. Yamauchi J, Mishima C, Fujiwara M, Nakayama S, Ishii N. Steady-state force-velocity relation in human multi-joint movement determined with force clamp analysis. J Biomech. 2007;40(7):1433-42.

11. Cuk I, Markovic M, Nedeljkovic A, Ugarkovic D, Kukolj M, Jaric S. Force-velocity relationship of leg extensors obtained from loaded and unloaded vertical jumps. Eur J Appl Physiol. 2014;114(8):1703-14.

12. Ćosić M, Đurić S, Živković M, Nedeljković A. Force-velocity relationship of leg extensors obtained from three different types of load. Facta Univ Ser Phys Educ Sport. 2018;15(3):467.

13. Fenn WO, Marsh BS. Muscular force at different speeds of shortening. J Physiol. 1935;85(3):277-97.

14. Hauraix H, Dorel S, Rabita G, Guilhem G, Nordez A. Muscle fascicle shortening behaviour of vastus lateralis during a maximal forcevelocity test. Eur J Appl Physiol. 2017;117(2):289-99.

15. Hill AV. The heat of shortening and the dynamic constants of muscle. Proc $R$ Soc London Ser B - Biol Sci. 1938;126(843):136-95

16. Ritchie JM, Wilkie DR. The dynamics of muscular contraction. J Physiol. 1958;143(1):104-13.

17. Edman KA. Double-hyperbolic force-velocity relation in frog muscle fibres. J Physiol. 1988;404(1):301-21.

18. Iglesias-Soler E, Mayo X, Rial-Vázquez J, et al. Reliability of force-velocity parameters obtained from linear and curvilinear regressions for the bench press and squat exercises. J Sports Sci. 2019;37(22):2596-603.

19. Rivière JR, Rossi J, Jimenez-Reyes P, Morin JB, Samozino P. Where does the One-Repetition Maximum Exist on the Force-Velocity Relationship in Squat? Int J Sports Med. 2017;38(13):1035-43.

20. Alcazar J, Pareja-Blanco F, Rodriguez-Lopez C, et al. Comparison of linear, hyperbolic and double-hyperbolic models to assess the force-velocity relationship in multi-joint exercises. Eur J Sport Sci. 2020;1-28.

21. Alcazar J, Navarro-Cruz R, Rodriguez-Lopez C, Vila-Maldonado S, Ara I, Alegre LM. The double-hyperbolic force-velocity relationship in humans. Acta Physiol. 2019;226(4):e13165.

22. Alcazar J, Csapo R, Ara I, Alegre LM. On the Shape of the Force-Velocity Relationship in Skeletal Muscles: The Linear, the Hyperbolic, and the Double-Hyperbolic [Internet]. Front Physiol. 2019;10(June) available from: 
https://www.frontiersin.org/article/10.3389/fphys.2019.00769/full. doi:10.3389/fphys.2019.00769.

23. Hahn D, Herzog W, Schwirtz A. Interdependence of torque, joint angle, angular velocity and muscle action during human multi-joint leg extension. Eur J Appl Physiol. 2014;114(8):1691-702.

24. Ockham W. Quaestiones et decisiones in quattuor libros Sententiarum Petri Lombardi. 1495. 908 p.

25. Alexander RM. Modelling approaches in biomechanics. Philos Trans R Soc London Ser B Biol Sci. 2003;358(1437):1429-35.

26. Cuevas-Aburto J, Ulloa-Díaz D, Barboza-González P, Chirosa-Ríos LJ, García-Ramos A. The addition of very light loads into the routine testing of the bench press increases the reliability of the force-velocity relationship. PeerJ. 2018;6(September):e5835.

27. Rahmani A, Samozino P, Morin J-B, Morel B. A Simple Method for Assessing Upper-Limb Force-Velocity Profile in Bench Press. Int J Sports Physiol Perform. 2018;13(2):200-7.

28. Winter DA. Biomechanics and Motor Control of Human Movement. Hoboken, NJ, USA: John Wiley \& Sons, Inc.; 2009. Available from: http://doi.wiley.com/10.1002/9780470549148.

29. Hopkins WG, Marshall SW, Batterham AM, Hanin J. Progressive Statistics for Studies in Sports Medicine and Exercise Science: Med Sci Sport Exerc. 2009;41(1):3-13.

30. Rudsits BL, Hopkins WG, Hautier CA, Rouffet DM. Force-velocity test on a stationary cycle ergometer: methodological recommendations. J Appl Physiol. 2018;124(4):831-9.

31. Akaike H. A new look at the statistical model identification. IEEE Trans Automat Contr. 1974;19(6):716-23.

32. Burnham KP, Anderson DR. Model Selection and Multimodel Inference. New York, NY: Springer New York; 2004. 181-181 p. Available from: $h$ ttp://www.tandfonline.com/doi/abs/10.1198/tech.2003.s146.

33. Johnson JB, Omland KS. Model selection in ecology and evolution. Trends Ecol Evol. 2004;19(2):101-8.

34. Samozino P, Rivière JR, Rossi J, Morin J-B, Jimenez-Reyes P. How Fast Is a Horizontal Squat Jump? Int J Sports Physiol Perform. 2017;13(7):910-6.

35. Morin J-B, Samozino P, Murata M, Cross MR, Nagahara R. A simple method for computing sprint acceleration kinetics from running velocity data: Replication study with improved design. J Biomech. 2019;94(July):82-7.

36. Alcazar J, Rodriguez-Lopez C, Ara I, et al. The Force-Velocity Relationship in Older People: Reliability and Validity of a Systematic Procedure. Int J Sports Med. 2017;38(14):1097-104.

37. García-Ramos A, Feriche B, Pérez-Castilla A, Padial P, Jaric S. Assessment of leg muscles mechanical capacities: Which jump, loading, and variable type provide the most reliable outcomes? Eur J Sport Sci. 2017;17(6):690-8.

38. Valenzuela PL, Sánchez-Martínez G, Torrontegui E, Vázquez Carrión J, Montalvo Z, Haff GG. Should we base training prescription on the force-velocity profile? Exploratory study of its between-day reliability and differences between methods [Internet]. Int J Sports Physiol Perform. 2020; doi:10.1123/ijspp.2020-0308.

39. Navarro-Cruz R, Alcazar J, Rodriguez-Lopez C, et al. The Effect of the Stretch-Shortening Cycle in the Force-Velocity Relationship and Its Association With Physical Function in Older Adults With COPD. Front Physiol. 2019;10(March):1-11.

40. Jiménez-Reyes $P$, Samozino P, Morin JB. Optimized training for jumping performance using the force-velocity imbalance: Individual adaptation kinetics. PLoS One. 2019;14(5):1-20. 